\title{
BMJ Open Validation of handheld fundus camera with mydriasis for retinal imaging of diabetic retinopathy screening in China: a prospective comparison study
}

\author{
Baixiang Xiao (D) , ${ }^{1}$ Qinghua Liao, ${ }^{2}$ Yanping Li, ${ }^{3}$ Fan Weng, ${ }^{4}$ Ling Jin, ${ }^{1}$ \\ Yanfang Wang, ${ }^{1}$ Wenyong Huang, ${ }^{1}$ Jinglin Yi, ${ }^{3}$ Matthew J Burton, ${ }^{5}$ Jennifer LY Yip ${ }^{5}$
}

To cite: Xiao B, Liao Q, Li Y, et al. Validation of handheld fundus camera with mydriasis for retinal imaging of diabetic retinopathy screening in China: a prospective comparison study. BMJ Open 2020;10:e040196. doi:10.1136/ bmjopen-2020-040196

- Prepublication history for this paper is available online. To view these files, please visit the journal online (http://dx.doi org/10.1136/bmjopen-2020040196).

Received 07 May 2020 Revised 05 August 2020 Accepted 08 October 2020

Check for updates

(C) Author(s) (or their employer(s)) 2020. Re-use permitted under CC BY-NC. No commercial re-use. See rights and permissions. Published by BMJ.

${ }^{1}$ The State Key Laboratory of Ophthalmology, Zhongshan Ophthalmic Centre, Sun Yat-sen University, Guangzhou, China ${ }^{2}$ Zhenjiang District Hospital, Shaoguan, China

${ }^{3}$ Affiliated Eye Hospital of Nanchang University, Nanchang, China

${ }^{4}$ Yuexiu District Centre of Disease Control, Guangzhou, China

${ }^{5}$ London School of Hygiene and Tropical Medicine, London, UK

Correspondence to Dr Baixiang Xiao; xiaobaixiang2006@126.com and

Dr Wenyong Huang; 1220792380@qq.com

\section{ABSTRACT}

Objectives To investigate the clinical validity of using a handheld fundus camera to detect diabetic retinopathy (DR) in China.

Design and settings Prospective comparison study of the handheld fundus camera with a standard validated instrument in detection of DR in hospital and a community screening clinic in Guangdong Province, China.

Participants Participants aged 18 years and over with diabetes who were able to provide informed consent and agreed to attend the dilated eye examination with handheld tests and a standard desktop camera.

Primary and secondary outcome measures Primary outcome was the proportion of those with referable DR (R2 and above) identified by the handheld fundus camera (the index test) compared with the standard camera. Secondary outcome was the comparison of proportion of gradable images obtained from each test.

Results In this study, we examined 304 people (608 eyes) with each of the two cameras under mydriasis. The handheld camera detected 119 eyes (19.5\%) with some level of DR, 81 (13.3\%) of them were referable, while the standard camera detected 132 eyes $(21.7 \%)$ with some level of DR and $83(13.7 \%)$ were referable. It seems that the standard camera found more eyes with referable DR, although McNemar's test detected no significant difference between the two cameras.

Of the 608 eyes with images obtained by desktop camera, $598(98.4 \%)$ images were of sufficient quality for grading, $12(1.9 \%)$ images were not gradable. By the handheld camera, $590(97.0 \%)$ were gradable and $20(3.2 \%)$ images were not gradable.

The two cameras reached high agreement on diagnosis of retinopathy and maculopathy at all the levels of retinopathy.

Conclusion Although it could not take the place of standard desktop camera on clinic fundus examination, the handheld fundus camera showed promising role on preliminary DR screening at primary level in China. To ensure quality images, mydriasis is required.

\section{INTRODUCTION}

Diabetes mellitus (DM) is a major cause of morbidity and mortality worldwide, responsible for 1.5 million deaths in 2012. ${ }^{1}$ The
Strengths and limitations of this study

- Study subjects recruited for this study were from both outpatient department of hospital and community screening with the variety of diabetic retinopathy for the study comparison.

- Two experienced graders from tertiary eye institute graded the images captured by both cameras separately and reached full agreement on grading.

- To avoid bias from personnel, technicians were experienced with the standard camera and received full training in using both the handheld and standard cameras.

- We noticed high rate of images with poor quality without dilation at the pilot study and started to give mydriasis for all the participants at the formal study, so that there were lack of data on non-mydriasis.

ageing population, rising levels of obesity and lifestyle changes will increase this figure of DM further. In China, the prevalence of diabetes increased dramatically in the last 30 years, with recent prevalence estimates in adults of $10.9 \% .^{2}$

Diabetic retinopathy (DR) is a common microvascular complication causing retinal haemorrhage and oedema in people with DM $(\mathrm{PwDM})$. This reduces visual acuity $(\mathrm{VA})$ at a late stage in the condition/disease or when the macular is affected when the treatment is not optimal. Worldwide, it is one of the most common causes of visual impairment, particularly in working age adults, with significant economic impact. ${ }^{3}$ In China, a systematic review showed that approximately one in five people diagnosed with diabetes has some level of DR, which is similar to other highincome countries. ${ }^{45}$

There are effective strategies to prevent and treat DR. The risk of vision loss can be reduced with metabolic management, early 
detection through screening and appropriate laser intravitreous injection or vitrectomy.

DR screening (DRS) and appropriate referral for treatment have been shown to reduce blindness from DR. ${ }^{6}$ However, studies have shown that in rural areas of China, only $10 \%$ of those with DR are diagnosed and treated. ${ }^{4}$ This indicates a need to ensure accessible DRS services to reduce potential eye health inequalities.

The primary healthcare providers in China encourage PwDM to register and receive an annual health check in the rural township clinic and urban community health centre to monitor patients' glucose levels and detect potential complications. Primary care doctors are not trained in eye care, and PwDM are asked to travel to county hospitals for eye examinations at their own expense, which results in inequitable access.

Fundus cameras have now been installed rapidly in most of the county level hospitals since the national study on eye service in 2014 found that only $10 \%$ of the secondary level hospitals had the capacity to take fundus images (data not been published). Outreach services are limited due to the lack of specialist eye care staff in secondary care, which also leads to variation in screening uptake and consequently treatment of DR.

In a clinical review of PwDM in Guangzhou, 43.2\% of people in tertiary and community urban setting had never received an eye examination. In rural clinics, $68.7 \%$ had never received an eye examination. ${ }^{7}$

Provision of screening at primary care level can increase uptake $^{8-10}$; however, the cost of providing all primary care clinics in China with a digital camera would be prohibitive, together with implications of additional training of staff and maintenance of equipment. DR services are in their infancy in China.

The Zhongshan Ophthalmic Centre (ZOC), Sun Yat-sen University, is a leading eye institution, and well placed to plan and develop a DR service model in China. Currently, there are no sustainable and scalable models for delivery of DR services in rural China.

The aim of this study is to validate retinal images from a handheld portable retinal camera for DRS, using a desktop digital camera as the comparison. Findings from this study will lead to further investigation of the role of handheld cameras for the acquisition of retinal images and improving access and increasing uptake of DRS in primary care clinics in China.

\section{METHODS}

All participants provided written, informed consent. Patients with referable diabetic or other eye diseases were referred to ZOC for further examination or treatment. The study fulfilled the tenets of the Declaration of Helsinki.

\section{Patient and public involvement statement}

We talked with participants about the purpose of the study, how it could be done and what support needed from them before and during the study. These information were also disseminated by primary health workers before consent obtained from each of the participant

This was a prospective comparison study of the handheld fundus camera (index test) of Horus Scope DEC $200^{11}$ with the desktop digital camera (standard test), Canon (model CR-2), in detection of referable DR.

\section{Population}

Eligible participants were all those aged 18 years and over with diabetes who were able to provide informed consent and agreed to attend for dilated eye examination with both index and standard tests. Diabetes was identified by self-report as well as definite medical records in hand, referral by endocrinologist, or registration in the primary healthcare centres.

Participants were recruited from hospitals in Zhenjiang District (Shaoguan prefecture), hospitals in Chenghai District (Shantou city) and community health centres in Yuexiu District (Guangzhou city) in consecutive series in Guangdong Province, China, with a range of DR severity, including patients without DR in order to obtain a representative spectrum of patients in this study.

\section{Sample size}

A sample size of 262 patients has $80 \%$ power and $5 \%$ significance level to detect a $6 \%$ difference in proportion of gradable images between the index and the standard test, where the standard test will produce $90 \%$ gradable images.

\section{Training}

The pilot study was conducted in the community screening clinic in Guangzhou city. Technicians with at least 1-year experience of operation for the handheld camera and desktop camera examined 30 cases with both undilated and dilated pupils according to the assessment on the quality of images and operation on the camera by an ophthalmologist.

In the other study sites, we trained technicians with experiences of fundus cameras to capture images on the use of the handheld camera as well as the standard camera to ensure a standardised process, including 'instal/uninstall', how to capture images with both camera and fill the data collection form. They each practiced on the handheld camera for approximately 20 pilot cases, closely supervised by experienced technician until there were no more questions on using the camera and quality of the images taken were considered acceptable by the senior ophthalmologist. The training took 2 hours and the trainer observed for the first whole day before technicians operated independently.

\section{Data collection}

A data collection form was developed, including information on the patient's age, gender, education, profession, VA (by illuminated Snellen visual chart), use of glasses, self-assessed visual function, history of eye examinations and fundus photocoagulation, history of DM, 
complications, treatment of DM and hypertension (HP), fasting glucose on the day of fundus photo taken, which camera the participants preferred and why. Treatment options for DM and HP were given in multiple choices, that was five options for DM as: insulin, oral medicine, diet, Chinese Traditional Medicine (CTM) and no treatment, and four options for HP as: oral medicine, diet, CTM and no treatment.

\section{Pilot study}

Without dilation, from both cameras, approximately onethird of the images from the first eye (always right eye) were of poor quality (including ungradable and poor but still gradable), and $10 \%$ were ungradable. We asked participants to rest in a darkened room for 2 min after photographs were taken from the first eye, and up to 15 min for those with poor quality images, to facilitate pupil dilation, but there was a higher proportion of poor quality pictures from the second eye $(40 \%)$ with both cameras (data not presented). This took 1 day in Guangzhou and $30 \mathrm{PwDM}$ were examined with an ophthalmologist onsite for the assessment.

Due to the high rate of poor images and patients' dissatisfaction from waiting in the dark room for second camera and sometimes even for the second eye, we decided to give mydriasis to every participant for image taken in the formal study.

\section{The formal study}

All participants had the following tests in sequence during one visit in the clinic within 2 hours of the first photograph to ensure photographs from both cameras were obtained under maximal dilation: participant's basic information, VA test, anterior segment examination under slit lamp by an ophthalmologist, intraocular pressure test, dilation of both eyes, fundus photograph of both eyes by the handheld retinal camera and the desk top digital camera and finally, the questions on preference of and comments on the cameras. We randomly assigned patients to a different sequence of cameras, with sufficient time in between to minimise discomfort.

Two photos were taken for each eye of all the participants by each of the two cameras. One centred on the macula and the other on the papilla optica. One technician operated both the handheld and standard cameras for participants in each of the three study sites (total 3). The technicians for the cameras were asked the advantages and disadvantages of both cameras, the ease of use, graders were asked the acceptability of mode of photography.

The fundus photographs from all tests were uploaded on the DR online grading system and graded independently at the grading centre in ZOC where the experienced graders were masked to the mode of photograph where possible.

The two graders graded all the study images separately and then together to compare whether there was disagreement on the grading results, an ophthalmologist was used as an arbitration grader. They discussed any disagreement until they reached consensus. They had been trained appropriately as the graders in ZOC's grading centre, which serves for over 70 secondary hospitals across the country in programmes. They both had been working in this centre for at least 5 years and constantly monitored by ophthalmologist supervisors on quality of their work.

\section{Image quality}

Images were considered of good quality when features were focused, well-illuminated retinal field, showing clarity of the fundus vessels and any retinopathy. If the images were only partially focused, illuminated or retinal field showed, they were defined as poor but still gradable. If any retinopathy was detected, either DR or non-DR, the images were also defined as gradable. If images are blurred without recognition of the retinal vessels or retinopathy features, they are defined as not gradable. The patients with not gradable images were then referred to the ophthalmologist for further examination.

\section{Grading system}

To define the fundus pathology and grade the retinal changes, we used grading definitions for referable disease by the English NHS Diabetic Eye Screening Programme. ${ }^{12}$ That is, R0 is categorised as the absence of any DR feature, including microaneurysms. Microaneurysm with or without exudation is categorised as R1 for its only presence without other DR features.

The eye is categorised as R2 if any of the following features are present: venous beading, cotton wool spots, venous reduplication, multiple blot haemorrhages and intraretinal microvascular abnormality.

If there is presenting proliferative retinopathy, that is, new blood vessels or haemorrhage within retina or in vitreous, or vitreous traction, the eye is categorised as $\mathrm{R} 3 \mathrm{a}$. If there is evidence of retinal laser treatment and DR features are stable, the eye is categorised as R3s. The presence of microaneurysms, haemorrhage or exudes within two disc diameters of the centre of the fovea is categorised as M1.

\section{Statistics analysis}

The data were presented as mean (SD) or median (IQR) for continuous variable and frequency $(\%)$ for categorical variable. Participants' age was categorised by interval of 10 years. Age at diagnosis of diabetes and HP was categorised by interval of 5 years. The cut-offs of 0.05 and 0.3 were used to describe VA in better-seeing eye. The data were analysed by eyes. McNemar's test was performed for comparing the standard and portable cameras. The inter-rater reliability between two cameras was measured by Cohen's kappa coefficient (95\% CI). Sensitivity, specificity, positive predictive value and area under the receiver operator curve with $95 \% \mathrm{CI}$ were calculated to indicate the accuracy of diagnosis by two cameras. All statistical analyses were performed using a commercially 
available software package (Stata V.13.1, StataCorp, College Station, Texas, USA).

\section{Comments on the cameras}

Comments from both staff and the patients were simply listed and similar ones were categorised together until there were no more new comments and repeated ones were included together as one comment.

\section{RESULTS}

\section{Participants' characteristics}

Patient recruitment started in June 2018 simultaneously in three places and ended up a total of 305 people with diabetes examined by the end of the year. Mean age of the participants was 61.3 years $(\mathrm{SD}: \pm 10.1)$ and almost half $(41.6 \%)$ were between 61 years and 70 years. Among them, $165(54.1 \%)$ were female (table 1). Over one-third received high school and above education. Over half $(53.6 \%)$ of the participants were retired and approximately $10 \%$ unemployed. Mean age at diagnosis of diabetes was 52.4 years $(\mathrm{SD}: \pm 10.5)$. Among these participants, around one-third had diabetes for less than 5 years, one-third for 6-10 years and the rest had over 10 years. Only $12(3.9 \%)$ people had diabetes for over 20 years. The median duration of diabetes was 5 years (4-12 years).

On study days, we detected only $108(35.4 \%)$ participants with fasting glucose below $7 \mathrm{mmol} / \mathrm{L}$ (table 1), which is clinically considered as good control. Insulin was used by $112(36.7 \%)$ people and $262(85.9 \%)$ were taking oral medication, 12 (4\%) reported no treatment, not even diet.

HP was detected in $48.2 \%$ participants, nephropathy in $7.5 \%$ and cardiovascular disease in $11.2 \%$. Of these 305 PwDM, $252(82.6 \%)$ did not have any complications of diabetes. Mean age at diagnosis of HP was 54.4 years (SD \pm 11.1 ). Of the 147 participants with HP, eight could not remember when the problem started or being diagnosed, $59(40.1 \%)$ people were diagnosed less than 5 years and $10(6.8 \%)$ people over 20 years ago (table 1$)$. Majority $(85.0 \%)$ of these people with HP were taking oral medication and $16(10.9 \%)$ received no treatment.

Of the 305 participants, $276(90.5 \%)$ had presenting VA equal to or over $0.3,3(0.98 \%)$ below 0.05 , while by self-assessment, only $11(3.61 \%)$ expressed that they had excellent VA, 81 (26.6\%) said their VA was good and $81(26.6 \%)$ felt their VA was poor (table 2). Over half $(59.7 \%)$ of the participants did not have their eyes examined by medical staff in the previous year. Twenty-one $(6.89 \%)$ people had received laser photocoagulation.

\section{Agreement by the two graders}

Grading results from the two graders reached agreement on 606 eyes and disagreed on only two eyes for R1. They reached to consensus after discussion.
Table 1 Demographic information of participants with diabetes ( $\mathrm{N}=305$ subjects)

\begin{tabular}{|c|c|}
\hline Characteristics & Statistics \\
\hline \multicolumn{2}{|l|}{ Recruited sites, n (\%) } \\
\hline Community (registered in) & $89(29.2)$ \\
\hline Hospital (being referred by physicians) & $141(46.2)$ \\
\hline $\begin{array}{l}\text { Hospital (walk in with medical record of } \\
\text { diabetes) }\end{array}$ & $75(24.6)$ \\
\hline \multicolumn{2}{|l|}{ Age, years, n (\%) } \\
\hline $18-31$ & $5(1.64)$ \\
\hline $31-40$ & $4(1.31)$ \\
\hline $41-50$ & $27(8.85)$ \\
\hline $51-60$ & $97(31.8)$ \\
\hline $61-70$ & $127(41.6)$ \\
\hline$>70$ & $45(14.8)$ \\
\hline Mean (SD) & $61.3(10.1)$ \\
\hline Female sex, $\mathrm{n}(\%)$ & $165(54.1)$ \\
\hline \multicolumn{2}{|l|}{ Educational level, n (\%) } \\
\hline No formal education & $68(22.3)$ \\
\hline Elementary school & $75(24.6)$ \\
\hline Junior school & $45(14.8)$ \\
\hline High school & $89(29.2)$ \\
\hline College or above & $28(9.18)$ \\
\hline \multicolumn{2}{|l|}{ Occupation } \\
\hline Farmer & $15(4.93)$ \\
\hline Worker & $30(9.87)$ \\
\hline Officer/clerk & $20(6.58)$ \\
\hline Technician & $9(2.96)$ \\
\hline Self-employed/freelance professional & $26(8.55)$ \\
\hline Educational/medical staff & $6(1.97)$ \\
\hline Retired & 164 (53.8) \\
\hline Unemployed & 35 (11.5) \\
\hline $\begin{array}{l}\text { Age at diagnosis of diabetes, years, mean } \\
\text { (SD) }\end{array}$ & $52.4(10.5)$ \\
\hline
\end{tabular}

Duration of diabetes, years, $\mathrm{n}(\%)$

$\begin{array}{ll}1-5 & 109(35.7) \\ 6-10 & 104(34.1) \\ 10-15 & 52(17.1) \\ 16-20 & 28(9.18) \\ >20 & 12(3.93) \\ \text { Median (IQR) } & 5(4-12)\end{array}$

Fasting glucose level on the day of image taken, $\mathrm{mmol} / \mathrm{L}, \mathrm{n}$ (\%)

\begin{tabular}{|c|c|}
\hline$\leq 7$ & $108(35.4)$ \\
\hline$>7$ & $197(64.6)$ \\
\hline \multicolumn{2}{|c|}{ Current treatment of DM, n (\%) } \\
\hline Insulin & $112(36.7)$ \\
\hline Medicine & $262(85.9)$ \\
\hline
\end{tabular}




\begin{tabular}{|c|c|}
\hline Characteristics & Statistics \\
\hline Diet control & $185(60.7)$ \\
\hline CTM & $58(19.0)$ \\
\hline No treatment & $12(3.93)$ \\
\hline HP, n (\%) & $147(48.2)$ \\
\hline Age at diagnosis of HP, year, mean (SD) & $54.4(11.1)$ \\
\hline \multicolumn{2}{|l|}{ Duration of HP, years, $n(\%)$} \\
\hline $1-5$ & $59 / 147(40.1)$ \\
\hline $6-10$ & 42/147 (28.6) \\
\hline $10-15$ & $18 / 147(12.2)$ \\
\hline $16-20$ & 10/147 (6.8) \\
\hline$>20$ & $10 / 147(6.8)$ \\
\hline Not sure when HP started & 8/147 (5.4\%) \\
\hline Median (IQR) & $7(3-12)$ \\
\hline \multicolumn{2}{|l|}{ Diabetic complications except HP, n (\%) } \\
\hline Nephropathy & $23(7.54)$ \\
\hline Cardiovascular & $34(11.2)$ \\
\hline Ulcerated arms/legs & $8(2.62)$ \\
\hline None & $252(82.6)$ \\
\hline \multicolumn{2}{|l|}{ Current treatment of HP, $\mathrm{n}(\%)$} \\
\hline Tablets & $125 / 147(85.0)$ \\
\hline Diet & $77 / 147$ (52.4) \\
\hline Traditional & 28/147 (19.0) \\
\hline No treatment & 16/147 (10.9) \\
\hline
\end{tabular}

*Eight participants could not remember when the HP started/ diagnosed.

CTM, Chinese Traditional Medicine; DM, diabetes mellitus; HP, hypertension.

\begin{tabular}{ll}
$\begin{array}{l}\text { Table } 2 \\
\text { treatment situation ( } \mathrm{N}=305 \text { subjects) }\end{array}$ & $\mathbf{n}(\%)$ \\
\hline & \\
\hline $\begin{array}{l}\text { Visual acuity of better eye, } \mathrm{n}(\%) \\
<0.05\end{array}$ & $3(0.98)$ \\
$\geq 0.05$ but $<0.3$ & $26(8.52)$ \\
\hline 0.3 & $276(90.5)$ \\
Self-assessed visual acuity, $\mathrm{n}(\%)$ & $11(3.61)$ \\
\hline Excellent & $22(7.21)$ \\
\hline Very good & $81(26.6)$ \\
\hline Good & $110(36.1)$ \\
\hline Fair & $81(26.6)$ \\
\hline Poor & $123(40.3)$ \\
Frequency of having eye examinations, $\mathrm{n}(\%)$ & $182(59.7)$ \\
\hline At least once in the last year & $21(6.89)$ \\
\hline No eye examination in the last year & \\
\hline Whether received photocoagulation, $\mathrm{n}(\%)$ &
\end{tabular}

Table 3 The quality of images ( $\mathrm{N}=610$ eyes)

\begin{tabular}{llll}
\hline Items & Desktop & Portable & P value* \\
\hline $\begin{array}{l}\text { Number of gradable } \\
\text { images } \dagger\end{array}$ & $598(98.7)$ & $590(96.9)$ & 0.064 \\
$\begin{array}{l}\text { Number good Images, } \mathrm{n} \\
(\%) \dagger\end{array}$ & $482(79.3)$ & $479(78.7)$ & 0.745 \\
$\begin{array}{l}\text { Number of poor but still } \\
\text { gradable, } \mathrm{n}(\%) \dagger\end{array}$ & $116(19.1)$ & $111(18.2)$ & 0.486 \\
\hline
\end{tabular}

*McNemar's test was used for comparing desktop and portable cameras.

†^2 (2/305, 0.66\%) eyes had missing data.

Image gradeability, referable eyes and agreement analysis Of the 305 people (610 eyes) examined, 1 patient (2 eyes) had the images duplicated with the previous patient owing to the wrong saving name in the computer, which left 608 eyes for grading. From desktop camera, 482 (79.3\%) images were of good quality and gradable, $116(19.1 \%)$ images were poor but still gradable and $12(1.9 \%)$ images were not gradable (table 3 ). From the handheld camera, $479(78.7 \%)$ images were of good quality and gradable, $111(18.2 \%)$ images were of poor quality, but still gradable and $20(3.2 \%)$ images were not gradable. Between the two groups of good and poor quality but still gradable images by the two cameras, McNemar's test found no significant difference, while the two groups added together, images taken by desktop gained slightly better quality than handheld, although the difference was not significant $(\mathrm{p}>0.05 \%)$.

For the non-gradable eyes, the two cameras agreed on five eyes, two of which had vitreous opacity, the other three eyes had dense cataract. There was one eye captured as R1 by handheld camera, but the image captured by desktop was non-gradable as handheld camera happened to capture some peripheral microaneurysms although images taken by both cameras were poor from this cataractous eye.

There were cataracts in eight eyes and ascertained as R1 by desktop camera, but not gradable by the handheld camera.

There were 14 eyes graded as R1 by the desktop camera, but ungradeable by the handheld camera.

In total, there were 132 eyes $(21.7 \%)$ with evidence of retinopathy (R1+R2+R3) (table 4), from images taken by desktop camera and 119 eyes $(19.5 \%)$ by handheld camera. We detected referable retinopathy at R2 and above in 83 eyes $(13.7 \%)$ from the desktop camera and 81 eyes $(13.3 \%)$ from the handheld camera, with no evidence of a statistically significant difference. R3 was detected in 28 eyes $(4.6 \%)$ by both handheld and desktop cameras. Of the 132 eyes with some level of retinopathy, $79(59.8 \%)$ eyes had macular involvement by standard camera.

The two cameras reached high agreement on diagnosis of retinopathy and maculopathy at the levels of $\mathrm{R} 1$ (kappa coefficient (KC) was 0.79), $\mathrm{R} 2(\mathrm{KC}=0.96), \mathrm{R} 3(\mathrm{KC}=1.0)$, M1 $(\mathrm{KC}=0.94)$ and other lesion $(\mathrm{KC}=0.82)$ (table 5). 
Table 4 Grading results by the two cameras

\begin{tabular}{|c|c|c|c|c|c|}
\hline & & & By desk & camera & \\
\hline & & & Present & Absent & Total \\
\hline & $\mathrm{R} 1$ & Present & 35 & 3 & 38 \\
\hline portable & & Absent & 14 & 532 & 546 \\
\hline & & Total & 49 & 535 & 584 \\
\hline & $\mathrm{R} 2$ & Present & 52 & 1 & 53 \\
\hline & & Absent & 3 & 528 & 531 \\
\hline & & Total & 55 & 529 & 584 \\
\hline & R3 & Present & 28 & 0 & 28 \\
\hline & & Absent & 0 & 556 & 556 \\
\hline & & Total & 28 & 556 & 584 \\
\hline & M1 & Present & 72 & 1 & 73 \\
\hline & & Absent & 7 & 504 & 511 \\
\hline & & Total & 79 & 505 & 584 \\
\hline & OL & Present & 14 & 2 & 16 \\
\hline & & Absent & 4 & 564 & 568 \\
\hline & & Total & 18 & 566 & 584 \\
\hline
\end{tabular}

OL, other lesion.

We identified 49 eyes at $\mathrm{R} 1$ by the desktop camera and 38 eyes by the handheld camera, which resulted in a sensitivity of $71.4 \%$ (95\% CI: 56.7 to 83.4 ), specificity of $99.4 \%$ (95\% CI: 98.4 to 99.9$)$ and positive predictive value (PPV) of $92.1 \%$ (95\% CI: 78.6 to 98.3 ).

At the level of referable retinopathy at R2, the desktop camera detected 55 eyes and handheld detected 53 eyes, resulting in a sensitivity of $94.6 \%$ (95\% CI: 84.0 to 98.9), specificity of $99.8 \%$ (95\% CI: 99 to 100) and PPV to $98.1 \%$ (95\% CI: 89.9 to 100). While for R3, the two cameras reached $100 \%$ agreement. The desktop camera captured six more eyes with maculopathy, while the handheld one did not detect maculopathy in these eyes and a
Table 6 Camera preferred by both patients and technician ( $\mathrm{N}=305$ subjects)

\begin{tabular}{ll}
\hline & $\mathbf{n}(\%)$ \\
\hline Camera preferred by patients & \\
Standard & $114(37.4)$ \\
Portable & $34(11.1)$ \\
Same & $157(51.5)$ \\
\hline
\end{tabular}

sensitivity of $91.1 \%$ (95\% CI: 82.6 to 96.4 ), specificity of 99.6\% (95\% CI: 98.9 to 100 ) and PPV of $98.6 \%$ (95\% CI: 92.6 to 100). The desktop camera also captured two more eyes with other lesions, which the handheld camera had not.

\section{Camera preference by both patients and technicians}

Approximately half (51.2\%) of the participants had no preference for either of the two cameras, $114(37.4 \%)$ people preferred the desktop camera and $34(11.1 \%)$ said the handheld one was preferred (table 6). Those preferring the standard camera gave reasons as follows: flash light for images taken by the standard camera was not so bright as the handheld one; it looked more complicated and was bigger, so that should be better, as recognised by most of non-medical people of the medical equipment and it was more convenient for height adjusting as it was on an elevator platform. Those participants who felt handheld was better gave reasons of simplicity, looking smart with easy mobilisation of the whole machine with or without the foldable stand (frame) for patient's chin rest.

Comments from the three experienced technicians on the two cameras were: 'for the community DR screening, the handheld one is enough'. 'It is easy to install and pack up.' They also pointed out that, with the simple stand for patient's chin rest, focusing process became much easier and quicker than when without.

Table 5 Accuracy of diagnosis $(\mathrm{N}=610 \text { eyes })^{\star}$

\begin{tabular}{|c|c|c|c|c|c|c|c|}
\hline \multicolumn{8}{|c|}{ By desktop camera } \\
\hline & & $\begin{array}{l}\text { Kappa }(95 \% \\
\text { Cl) }\end{array}$ & $\begin{array}{l}\text { Sensitivity (95\% } \\
\text { Cl) }\end{array}$ & $\begin{array}{l}\text { Specificity }(95 \% \\
\mathrm{Cl})\end{array}$ & $\begin{array}{l}\text { Positive predictive } \\
\text { value }(95 \% \mathrm{Cl})\end{array}$ & $\begin{array}{l}\text { Negative predictive } \\
\text { value }(95 \% \mathrm{Cl})\end{array}$ & AUC (95\% Cl) \\
\hline \multirow{5}{*}{$\begin{array}{l}\text { By } \\
\text { portable } \\
\text { camera }\end{array}$} & $\mathrm{R} 1$ & $\begin{array}{l}0.79 \text { (0.69 to } \\
0.89)\end{array}$ & $\begin{array}{l}71.4 \%(56.7 \% \text { to } \\
83.4 \%)\end{array}$ & $\begin{array}{l}99.4 \%(98.4 \% \text { to } \\
99.9 \%)\end{array}$ & $\begin{array}{l}92.1 \%(78.6 \% \text { to } \\
98.3 \%)\end{array}$ & $\begin{array}{l}97.4 \%(95.7 \% \text { to } \\
98.6 \%)\end{array}$ & $\begin{array}{l}0.85 \text { ( } 0.79 \text { to } \\
0.92)\end{array}$ \\
\hline & $\mathrm{R} 2$ & $\begin{array}{l}0.96(0.92 \text { to } \\
0.999)\end{array}$ & $\begin{array}{l}94.6 \%(84.9 \% \text { to } \\
98.9 \%)\end{array}$ & $\begin{array}{l}99.8 \%(99 \% \text { to } \\
100 \%)\end{array}$ & $\begin{array}{l}98.1 \%(89.9 \% \text { to } \\
100 \%)\end{array}$ & $\begin{array}{l}99.4 \%(98.4 \% \text { to } \\
99.9 \%)\end{array}$ & $\begin{array}{l}0.97(0.94 \text { to } \\
1.00)\end{array}$ \\
\hline & R3 & $\begin{array}{l}1.00(1.00 \text { to } \\
1.00)\end{array}$ & $\begin{array}{l}100 \%(87.7 \% \text { to } \\
100 \%)\end{array}$ & $\begin{array}{l}100 \%(99.3 \% \text { to } \\
100 \%)\end{array}$ & $\begin{array}{l}100 \%(87.7 \% \text { to } \\
100 \%)\end{array}$ & $\begin{array}{l}100 \%(99.3 \% \text { to } \\
100 \%)\end{array}$ & $\begin{array}{l}1.00(1.00 \text { to } \\
1.00)\end{array}$ \\
\hline & M1 & $\begin{array}{l}0.94(0.90 \text { to } \\
0.98)\end{array}$ & $\begin{array}{l}91.1 \%(82.6 \% \text { to } \\
96.4 \%)\end{array}$ & $\begin{array}{l}99.8 \%(98.9 \% \text { to } \\
100 \%)\end{array}$ & $\begin{array}{l}98.6 \%(92.6 \% \text { to } \\
100 \%)\end{array}$ & $\begin{array}{l}98.6 \%(97.2 \% \text { to } \\
99.4 \%)\end{array}$ & $\begin{array}{l}0.95 \text { ( } 0.92 \text { to } \\
0.99)\end{array}$ \\
\hline & OL & $\begin{array}{l}0.82(0.68 \text { to } \\
0.96)\end{array}$ & $\begin{array}{l}77.8 \%(52.4 \% \text { to } \\
93.6 \%)\end{array}$ & $\begin{array}{l}99.7 \%(98.7 \% \text { to } \\
100 \%)\end{array}$ & $\begin{array}{l}87.5 \%(61.7 \% \text { to } \\
98.4 \%)\end{array}$ & $\begin{array}{l}99.3 \%(98.2 \% \text { to } \\
99.8 \%)\end{array}$ & $\begin{array}{l}0.89(0.79 \text { to } \\
0.99)\end{array}$ \\
\hline
\end{tabular}

*Two eyes had missing data.

AUC, area under the receiver operator curve; OL, other lesion. 


\section{DISCUSSION}

We compared the quality of fundus images and the referable eyes with images taken by the standard Canon CR2 desktop and a simple Forus handheld fundus cameras from the same 305 PwDM in three places of Guangdong Province, China, and our analysis found no difference on proportion of gradable images, good images and number of eyes with referable retinopathy between the two cameras when mydriasis was used.

Training for those without experience was easy and relatively quick. The handheld camera is simply designed, easy to install and to pack up. The light and foldable stand designed for the handheld camera makes it possible to be carried by hand. Its images cover the same retinal field as the standard one.

In the English national screening programme for DR, Scanlon et al demonstrated that two images centred on the disc and macular with $45^{\circ}$ field camera achieved high sensitivities $(>87 \%)$ and specificities $(>86 \%)$ with low ungradable image rate of below $4.4 \%$ against the reference standard of seven-field stereophotography or an ophthalmologist using slit lamp biomicroscope. ${ }^{13} 14$ The two field images method was recommended for DRS and was used as the gold standard in this study.

Overall, there was no significant difference between using the handheld camera with dilation on detecting number of referable eyes with DR compared with the standard camera. The two cameras reached a high level of agreement on grading results of DR (kappa from 0.79 at R1 to 1.00 at R3). When authors looked at the images disagreed against findings from slit lamp, we noticed the following factors: for those eyes with cataract at the stage C3N3 to $\mathrm{C} 4 \mathrm{~N} 4^{15}$ and those with some level of vitreous opacity, the desktop camera could still capture images of blood vessels with some degree of clarity compared with the handheld camera.

In China, primary health staff commonly hesitate to give mydriasis for fundus examinations and are normally not confident to convince patients about the low risk of complications. ${ }^{16}$ In this study, the poor image rate reduced generally from over $30 \%$ to around $10 \%$. This in the meantime reduced the number of people referred to secondary care for further examination and saved resources. From the findings in this study, we would recommend mydriasis for DRS at primary level with training for primary health staff to obtain patient consent and manage potential complications in future programmes.

In this study, around one-third, 108 (35.4\%), of participants had their fasting glucose controlled at the recommended levels. Furthermore, 12 participants did not take any treatment for their DM, not even diet. Over half (59.7\%) of the participants had not had their eyes checked by medical staff in the previous year. This emphases the importance of health education and available services for DM patients in primary healthcare.

Approximately two-thirds of study participants were recuited from the clinics of secondary-level hospitals, who were diagnosed $\mathrm{PwDM}$ and had medical records at hand. The rest of one-third were community health unit registry. From them, we detected a similar lower rate of DR as other studies in China ${ }^{51718}$ compared to Singapore, India and the USA, ${ }^{19}$ while much lower than Handan eye study ${ }^{4}$ in North China and the more likely findings from other walk-in patients in six provinces in China. ${ }^{20}$ The study also detected $82.6 \%$ of the participants without any diabetic complications, which is mainly attributed to the median duration of diabetes was 5 years (4-12 years) and only $3.93 \%$ of participants had diabetes for over 20 years.

We detected a similar proportion of referable DR, high proportion of poor quality images at unmydriasis to the previous studies in China. ${ }^{21}$ Findings for the comparison of the two cameras are similar to the studies in other Asian countries like Sri Lanka ${ }^{22}$ and Thailand..$^{23}$

This study employed experienced eye care staff, who had been performing similar work for at least 3 years, to take the images with both desktop and the handheld cameras. There were also standardised procedures and training for all staff in the different sites, which would reduce measurement error. Graders were masked from patients' history and source of images, reducing ascertainment bias. Where the two cameras differed in their images, we carried out a slit lamp examination to determine the cause of the disagreement.

This was not a population-based study and, therefore, patient characteristics were not representative of DR with respect to severity of the diseases and its complications in the context of China; however, we included the full range of DR severity in our study population, mitigating spectrum bias.

\section{CONCLUSION}

A handheld fundus camera using mydriasis may have a role to play in preliminary DRS at the primary level in China and other settings worldwide, where desktop camera are not prevalent or easily accessible or where screening programmes are not operational.

Acknowledgements The authors acknowledge the doctors, technicians and nurses in Shaoguan Railway Hospital, Chenghai District Hospital and Community Health Centres in Yuexiu District, Guangzhou City, for their contributions to patient coordination during the data collection for this study. We also appreciate Dr James La Nauze from Australia for his contribution to English correction and revision of the manuscript.

Contributors BX: study design, training of the study teams, monitoring data collection and quality control, data cleaning, analysis as well as manuscript drafting and revision. QL: preliminary draft of the tables and manuscript, data analysis and critical revision of the manuscript. YL: monitoring of grading and valuable contribution to the revision of the manuscript. FW: data collection and valuable contribution to the study design. LJ: statistical analysis and helpful revision of the manuscript. YW: data cleaning and valuable contribution to the manuscript drafting. JY and WH: valuable contribution to the study design and revision of the manuscript. JLYY and MJB: substantial contributions to the conception, designing and revision of the manuscript as well as analysis and interpretation of the data.

Funding The study is fully funded by the State Key Laboratory of Ophthalmology, Zhongshan Ophthalmic Centre, Sun Yat-sen University.

Competing interests None declared. 
Patient and public involvement Patients and/or the public were involved in the design, or conduct, or reporting, or dissemination plans of this research. Refer to the Methods section for further details.

Patient consent for publication Not required.

Ethics approval Ethical approval of this study was obtained from both London School of Hygiene \& Tropical Medicine and Zhongshan Ophthalmic Centre, Sun Yat-sen University.

Provenance and peer review Not commissioned; externally peer reviewed.

Data availability statement Data are available upon reasonable request. Data of this study are saved in the department system and available by contacting the corresponding author.

Open access This is an open access article distributed in accordance with the Creative Commons Attribution Non Commercial (CC BY-NC 4.0) license, which permits others to distribute, remix, adapt, build upon this work non-commercially, and license their derivative works on different terms, provided the original work is properly cited, appropriate credit is given, any changes made indicated, and the use is non-commercial. See: http://creativecommons.org/licenses/by-nc/4.0/.

ORCID iD

Baixiang Xiao http://orcid.org/0000-0003-1987-4851

\section{REFERENCES}

1 World Health Organisation. Global report on diabetes (PDF, 2016). Available: https://www.who.int/publications-detail/global-report-ondiabetes [Accessed 6 Jan 2020].

2 Yang W, Lu J, Weng J, et al. Prevalence of diabetes among men and women in China. N Engl J Med 2010;362:1090-101.

3 Jönsson B. The economic impact of diabetes. Diabetes Care 1998;21:C7-10.

4 Wang FH, Liang YB, Zhang F, et al. Prevalence of diabetic retinopathy in rural China: the Handan eye study. Ophthalmology 2009;116:461-7.

5 Liu L, Wu X, Liu L, et al. Prevalence of diabetic retinopathy in mainland China: a meta-analysis. PLoS One 2012;7:e45264.

6 Liew G, Michaelides M, Bunce C. A comparison of the causes of blindness certifications in England and Wales in working age adults (16-64 years), 1999-2000 with 2009-2010. BMJ Open 2014;4:e004015

7 Wang D, Ding X, He M, et al. Use of eye care services among diabetic patients in urban and rural China. Ophthalmology 2010;117:1755-62.

8 Moreton RBR, Stratton IM, Chave SJ, et al. Factors determining uptake of diabetic retinopathy screening in Oxfordshire. Diabet Med 2017;34:993-9.
$9 \mathrm{Ng} \mathrm{JQ}$, Morlet N. Improving the uptake of screening for diabetic retinopathy. Med J Aust 2013;198:69-70.

10 Leese GP, Boyle P, Feng Z, et al. Screening uptake in a wellestablished diabetic retinopathy screening program: the role of geographical access and deprivation. Diabetes Care 2008;31:2131-5.

11 The website for introduction of the handheld camera Horus. Available: www.miis.com.tw [Accessed Dec 2019].

12 NHS Diabetic eye screening program. Available: https://assets. publishing.service.gov.uk/government/uploads/system/uploads/ attachment_data/file/582710/Grading_definitions_for_referrable_ disease_2017_new_110117.pdf [Accessed 18 Oct 2019].

13 Scanlon PH, Malhotra R, Greenwood RH, et al. Comparison of two reference standards in validating two field mydriatic digital photography as a method of screening for diabetic retinopathy. $\mathrm{Br} \mathrm{J}$ Ophthalmol 2003;87:1258-63.

14 Scanlon PH, Malhotra R, Thomas G, et al. The effectiveness of screening for diabetic retinopathy by digital imaging photography and technician ophthalmoscopy. Diabet Med 2003;20:467-74.

15 Karbassi M, Khu PM, Singer DM, et al. Evaluation of lens opacities classification system III applied at the slitlamp. Optom Vis Sci 1993;70:923-8.

16 Yan X, Liu T, Gruber L, et al. Attitudes of physicians, patients, and village health workers toward glaucoma and diabetic retinopathy in rural China: a focus group study. Arch Ophthalmol 2012;130:761-70.

17 Cui Y, Zhang M, Zhang L, et al. Prevalence and risk factors for diabetic retinopathy in a cross-sectional population-based study from rural southern China: Dongguan eye study. BMJ Open 2019;9:e023586.

18 Pan C-W, Wang S, Qian D-J, et al. Prevalence, awareness, and risk factors of diabetic retinopathy among adults with known type 2 diabetes mellitus in an urban community in China. Ophthalmic Epidemiol 2017;24:188-94.

19 Nangia V, Jonas JB, George R, et al. Prevalence and causes of blindness and vision impairment: magnitude, temporal trends and projections in South and central Asia. Br J Ophthalmol 2019;103:871-7.

20 Liu Y, Song Y, Tao L, et al. Prevalence of diabetic retinopathy among 13473 patients with diabetes mellitus in China: a cross-sectional epidemiological survey in six provinces. BMJ Open 2017;7:e013199.

21 Ding J, Zou Y, Liu N, et al. Strategies of digital fundus photography for screening diabetic retinopathy in a diabetic population in urban China. Ophthalmic Epidemiol 2012;19:414-9.

22 Piyasena MMPN, Yip JLY, MacLeod D, et al. Diagnostic test accuracy of diabetic retinopathy screening by physician graders using a handheld non-mydriatic retinal camera at a tertiary level medical clinic. BMC Ophthalmol 2019;19:89.

23 Suansilpong A, Rawdaree P. Accuracy of single-field nonmydriatic digital fundus image in screening for diabetic retinopathy. $J$ Med Assoc Thai 2008;91:1397-403. 